\title{
PROPERTIES OF COMPLETE METRIC SPACES AND THEIR APPLICATIONS TO COMPUTER SECURITY, INFORMATION AND COMMUNICATION TECHNOLOGY
}

\author{
N. B. OKELO \\ School of Mathematics and Actuarial Science, \\ Jaramogi Oginga Odinga University of Science and Technology, \\ P. O. Box 210 40601, Bondo Kenya \\ Email: bnyaare@yahoo.com
}

\begin{abstract}
Keywords: Expansive mapping Common fixed point; Dislocated metric; b -dislocated metric, Computer security and ICT
\end{abstract}

\begin{abstract}
Information and Communication Technology has faced a lot of challenges in terms of security of data and information. The aim of this paper is to prove some common fixed point theorems for expansive type mappings, firstly for a continuous mapping and secondly for a surjective mapping. These theorems are generalizations of some recent results in complete bdislocated metric space. The methodology involved is purely mathematical in nature with applications in computing. Moreover, we give various applications of these results in computer security, forensics and Information and Communication Technology.
\end{abstract}

\section{Introduction}

In this paper we give some properties in metric spaces and their applications to computing. Generalizations of Banach contractive principle have been obtained from many authors in several spaces. DS.Jaggi[1], Dass and Gupta [2] introduced rational expressions types of contractions. Also Rhoades [3] established a partial ordering for various definitions of contractive mappings. Hitzler and Seda, introduced the concept of dislocated metric space as a generalization of metric space. In 2005 Zeyada et al. initiated notion of dislocated quasimetric space. Further many authors proved fixed point theorems in such spaces. Motivated by the work of many researchers on fixed point results for expansive mappings in metric spaces, our aim in this paper is to establish and prove some fixed point theorems for expansive mappings in complete $b$ - dislocated metric spaces that is a generalization of dislocated metric space. The results obtained here in are important in computer engineering and technology, ICT and computer security.

\section{Preliminaries}

Definition 2.1 [6] Let $\mathrm{X}$ be a nonempty set and a mapping $d: X \times X \rightarrow[0, \infty]$ is called a dislocated metric (or simply $d$-metric) if the following conditions hold for any $x, y, z \in X$ :

i. If $d(x, y)=0$, then $x=y$

ii. $d(x, y)=d(y, x)$

iii. $d(x, y) \leq d(x, z)+d(z, y)$

The pair $(X, d)$ is called a dislocated metric space (or $d$-metric space for short). Note that when $x=y, d(x, y)$ may not be 0 .

Example 2.2 If $X=R$, then $d(x, y)=|x|+|y|$ defines a dislocated metric on X.

Definition 2.3 [6] A sequence $\left(x_{n}\right)$ in $d$-metric space $(X, d)$ is called: (1) a Cauchy sequence if, for given $\varepsilon>0$, there exists $n_{0} \in N$ such that for all $m, n \geq n_{0}$, we have $d\left(x_{m}, x_{n}\right)<\varepsilon$ or 
$\lim _{n, m \rightarrow \infty} d\left(x_{n}, x_{m}\right)=0$

(2) convergent with respect to $d$ if there exists $x \in X$ such that $d\left(x_{n}, x\right) \rightarrow 0$ as $n \rightarrow \infty$. In this case, $\mathrm{x}$ is called the limit of ${\left(x_{n}\right)}_{\text {and we write }} x_{n} \rightarrow x$.

A $d$-metric space $X$ is called complete if every Cauchy sequence in $X$ converges to a point in $X$.

Definition 2.4 [8] Let $\mathrm{X}$ be a nonempty set and a mapping $d: X \times X \rightarrow[0, \infty]$ is called a $b$ dislocated metric (or simply $b$-metric) if the following conditions hold for any $x, y, z \in X$ and $s \geq 1$.

i. If $d(x, y)=0$, then $x=y$

ii. $d(x, y)=d(y, x)$

iii. $d(x, y) \leq s[d(x, z)+d(z, y)]$

The pair $(X, d)$ is called a $b$-dislocated metric space. And the class of $b$-dislocated metric space is larger than that of dislocated metric spaces, since a $b$-dislocated metric is a dislocated metric when $s=1$.

Definition 2.5 [8] A sequence ${ }^{\left(x_{n}\right)}$ in a $b$-dislocated metric space $(X, d)$ converges with $d$ respect to if there exists $x \in X$ such that $d\left(x_{n}, x\right) \rightarrow 0$ as $n \rightarrow \infty$. In this case, $\mathrm{x}$ is called the limit of $\left(x_{n}\right)$ and we write $x_{n} \rightarrow x$.

Preposition 2.6[8] Limit of a convergent sequence in a $b$-dislocated metric space is unique.

Definition 2.7 [8] A sequence $\left(x_{n}\right)$ in $b$-dislocated metric space $(X, d)$ is called a Cauchy sequence if, given $\varepsilon>0$, there exists $n_{0} \in N$ such that for all $m, n \geq n_{0}$, we have $d\left(x_{m}, x_{n}\right)<\varepsilon$ or $\lim _{n, m \rightarrow \infty} d\left(x_{n}, x_{m}\right)=0$.

Preposition 2.8[8] Every convergent sequence in a $b$-dislocated metric space is Cauchy.

Definition 2.9[8] A $b$-dislocated metric space $(X, d)$ is called complete if every Cauchy sequence in $X$ is convergent.

Example 2.10 If $X=R$, then $d(x, y)=(x+y)^{2}$ defines a $b$-dislocated metric on $X$ with parameter $s=2$.

Some examples in the recent literature shows that in general a $b$-dislocated metric is not continuous.

\section{Main results}

In 1997, the mathematician D. S. Jaggi introduced for the first time the rational expression condition in metric spaces. In the present paper, we prove fixed point theorems for continuous expansive mapping in complete $b$-dislocated metric spaces using this rational expression.

Theorem3.1 Let $(X, d)$ be a complete $b$-dislocated metric space with a parameter $s \geq 1$, and $T$ a continuous self mapping on $X$ satisfying the following condition:

$$
d(T x, T y) \geq \beta \frac{d(x, T x) d(y, T y)}{d(x, y)}+\alpha d(x, y)
$$

for all $x, y \in X, x \neq y$ be an arbitrary point in $X$. Define inductively the sequence ${ }^{\left(x_{n}\right)}$ as follows: $T x_{n}=x_{n-1}$ for $n=1,2,3, \ldots$ By the condition (1) we have:

$$
\begin{aligned}
d\left(x_{n}, x_{n+1}\right) & =d\left(T x_{n+1}, T x_{n+2}\right) \\
& \geq \beta \frac{d\left(x_{n+1}, T x_{n+1}\right) d\left(x_{n+2}, T x_{n+2}\right)}{d\left(x_{n+1}, x_{n+2}\right)}+\alpha d\left(x_{n+1}, x_{n+2}\right)
\end{aligned}
$$




$$
\begin{aligned}
& =\beta \frac{d\left(x_{n+1}, x_{n}\right) d\left(x_{n+2}, x_{n+1}\right)}{d\left(x_{n+1}, x_{n+2}\right)}+\alpha d\left(x_{n+1}, x_{n+2}\right) \\
& =\beta d\left(x_{n}, x_{n+1}\right)+\alpha d\left(x_{n+1}, x_{n+2}\right)
\end{aligned}
$$

Therefore:

$$
d\left(x_{n+1}, x_{n+2}\right) \leq \lambda d\left(x_{n}, x_{n+1}\right)
$$

Where $\lambda=\frac{1-\beta}{\alpha}$ and $0 \leq \lambda<1$.

Similarly, we have $d\left(x_{n}, x_{n+1}\right) \leq \lambda d\left(x_{n-1}, x_{n}\right)$.

Continuing this process inductively, we obtain: $d\left(x_{n+1}, x_{n+2}\right) \leq \lambda^{n+1} d\left(x_{0}, x_{1}\right)$

Let $n, m \in N$ with $m>n$, and using the triangular inequality we have:

$$
\begin{aligned}
d\left(x_{n}, x_{m}\right) & \leq s\left[d\left(x_{n}, x_{n+1}\right)+d\left(x_{n+1}, x_{n+2}\right)\right] \\
& \leq s d\left(x_{n}, x_{n+1}\right)+s^{2} d\left(x_{n+1}, x_{n+2}\right)+\ldots+s^{m-n-1} d\left(x_{m-1}, x_{m}\right) \\
& \leq s \lambda^{n} d\left(x_{0}, x_{1}\right)+s^{2} \lambda^{n+1} d\left(x_{0}, x_{1}\right)+\ldots+s^{m-n-1} \lambda^{m-1} d\left(x_{0}, x_{1}\right) \\
& \leq s \lambda^{n} d\left(x_{0}, x_{1}\right)\left[1+s \lambda+(s \lambda)^{2}+(s \lambda)^{3}+\ldots \ldots . .\right] \\
& \leq \frac{s \lambda^{n}}{1-s \lambda} d\left(x_{0}, x_{1}\right)
\end{aligned}
$$

Since $0 \leq s \lambda<1$, and taking limit for $n \rightarrow \infty$ we get $\lim _{n, m \rightarrow \infty} d\left(x_{n}, x_{m}\right)=0$

So $\left(x_{n}\right)$ is a Cauchy sequence in complete $b$-dislocated metric space $X$, there exists an element $t_{0} \in X$ such that $\left(x_{n}\right) b$-dislocated converges to ${ }^{t_{0}}$. By continuity of T we have:

$$
t_{0}=\lim _{n \rightarrow \infty} x_{n}=\lim _{n \rightarrow \infty} T x_{n+1}=T\left(\lim _{n \rightarrow \infty} x_{n+1}\right)=T\left(t_{0}\right) \text {. Thus } t_{0} \text { is a fixed point of } T .
$$

Uniqueness. Let $t_{0}$ and $x$ be fixed point of $T$. That is $T t_{0}=t_{0}$ and $T x=x$. Then by (1)

$d\left(t_{0}, x\right)=d\left(T t_{0}, T x\right)$

$$
\begin{aligned}
& \geq \beta \frac{d\left(t_{0}, T t_{0}\right) d(x, T x)}{d\left(t_{0}, x\right)}+\alpha d\left(t_{0}, x\right) \\
& =\beta \frac{d\left(t_{0}, t_{0}\right) d(x, x)}{d\left(t_{0}, x\right)}+\alpha d\left(t_{0}, x\right) \\
& \geq \alpha d\left(t_{0}, x\right)
\end{aligned}
$$

This implies $(\alpha-1) d\left(t_{0}, x\right) \leq 0$, which gives $d\left(t_{0}, x\right)=0$. Similarly $d\left(x, t_{0}\right)=0$. Further $d\left(t_{0}, x\right)=d\left(x, t_{0}\right)=0$ implies $t_{0}=x$. Hence fixed point is unique.

Theorem 3.2 Let ${ }^{(X, d)}$ be a complete $b$-dislocated metric space with a parameter $s \geq 1, T$ a surjective self mapping on $X$ satisfying the following condition:

$$
d(T x, T y) \geq \beta \frac{d(x, T x) d(y, T y)}{d(x, y)}+\alpha d(x, y)
$$

for all $x, y \in X, x \neq y$ and the constants $\alpha, \beta$ non negative, where $\alpha+s \beta>s, \alpha>1$. Then, $T$ has a unique fixed point in $X$.

Proof. Let ${ }^{x_{0}}$ be an arbitrary point in $X$. Define inductively the sequence ${ }^{\left(x_{n}\right)}$ as follows:

$T x_{n}=x_{n-1}$ for $n=1,2,3, \ldots$. 
In the same manner by condition (1), we obtain that the sequence ${ }^{\left(x_{n}\right)}$ is a Cauchy sequence in $X$. Since $X$ is a complete $b$-dislocated metric space; hence the sequence ${ }^{\left(x_{n}\right)} b$-dislocated converges to ${ }^{t_{0} \in X}$. Since $T$ is a surjective mapping, then there exists a point $y \in X$, such that $T y=t_{0}$ Consider

$$
\begin{aligned}
d\left(x_{n}, t_{0}\right) & =d\left(T x_{n+1}, T y\right) \\
& \geq \beta \frac{d\left(x_{n+1}, T x_{n+1}\right) d(y, T y)}{d\left(x_{n+1}, y\right)}+\alpha d\left(x_{n+1}, y\right)
\end{aligned}
$$

In (3), taking limit as $n \rightarrow \infty$, we get: $0 \geq \alpha d\left(t_{0}, y\right)$, which implies $d\left(t_{0}, y\right)=0$.

Similarly $d\left(y, t_{0}\right)=0$. From $d\left(y, t_{0}\right)=d\left(t_{0}, y\right)=0$ we get $t_{0}=y$ Thus $t_{0}$ is a fixed point of $T$.

Uniqueness . Let $x$ be another fixed point of $T$ in $X$.

Again from condition (1) we have:

$$
\begin{aligned}
d\left(t_{0}, x\right) & =d\left(T t_{0}, T x\right) \\
& \geq \beta \frac{d\left(t_{0}, T t_{0}\right) d(x, T x)}{d\left(t_{0}, x\right)}+\alpha d\left(t_{0}, x\right) \\
& =\beta \frac{d\left(t_{0}, t_{0}\right) d(x, x)}{d\left(t_{0}, x\right)}+\alpha d\left(t_{0}, x\right) \\
& \geq \alpha d\left(t_{0}, x\right)
\end{aligned}
$$

This implies that $(\alpha-1) d\left(t_{0}, x\right) \leq 0$, so $d\left(t_{0}, x\right)=0$. Similarly we have $d\left(x, t_{0}\right)=0$.

Since $(X, d)$ is $b$-dislocated metric space, we get $t_{0}=x$. 'The proof is completed.

For replacing constant $\beta$ with zero in the above theorem we get the following corollary.

Corollary3.3 Let $(X, d)$ be a complete $b$-dislocated metric space with a parameter $s \geq 1$, and $T$ a continuous self mapping on $X$ satisfying the following condition:

$d(T x, T y) \geq \alpha d(x, y)$

for all $x, y \in X, x \neq y$ and the constants $\alpha$ where $\alpha>s$. Then, $T$ has a unique fixed point in $X$.

Example 3.4 Let be $X=[0,1]$ and let be a $b$-dislocated metric $d: X \times X \rightarrow R^{+}$defined as $d(x, y)=(x+y)^{2}$. Let be the self mappingT: $X \rightarrow X$ defined as $T x=3 x$. We notice that $(X, d)$ is a complete $b$-dislocated metric space and for all $x, y \in X$ have:

$$
d(T x, T y)=(3 x+3 y)^{2}=9(x+y)^{2} \geq \alpha d(x, y) .
$$

Thus all conditions of corollary 3.3 are satisfied and has a unique fixed point $x=0$.

Theorem 3.5 Let $(X, d)$ be a complete $b$-dislocated metric space with a parameter $s \geq 1$, and $T$ a continuous self mapping on $X$ satisfying the following condition:

$$
\begin{aligned}
& d(T x, T y)+\alpha \max \{d(x, T y), d(y, T x), d(x, T x)\} \\
& \geq \beta \frac{d(x, T x)[1+d(y, T y)]}{1+d(x, y)}+ \\
& \delta \frac{d(x, T x) d(y, T y)}{d(x, y)}+\gamma d(x, y)
\end{aligned}
$$

for all $x, y \in X, x \neq y$, and the constants $\alpha, \beta, \gamma, \delta$ non negative where $\beta+\delta+\frac{\gamma}{s}>1+\alpha+\alpha s, \gamma>1+2 \alpha, 1+\alpha s>\beta+\delta, \gamma>\alpha s$. Then, $T$ has a unique fixed point in $X$. 
Proof. Choose $x_{0} \in X$ arbitrary and define the iterative sequence ${ }^{(X, d)}$ as follows;

$T x_{n}=x_{n-1}$ for $n=1,2,3, \ldots$.

By condition of theorem have:

$$
\begin{aligned}
& d\left(T x_{n+1}, T x_{n+2}\right)+\alpha \max \left\{d\left(x_{n+1}, T x_{n+2}\right), d\left(x_{n+2}, T x_{n+1}\right), d\left(x_{n+1}, T x_{n+1}\right)\right\} \\
& \geq \beta \frac{d\left(x_{n+1}, T x_{n+1}\right)\left[1+d\left(x_{n+2}, T x_{n+2}\right)\right]}{1+d\left(x_{n+1}, x_{n+2}\right)}+ \\
& \delta \frac{d\left(x_{n+1}, T x_{n+1}\right) d\left(x_{n+2}, T x_{n+2}\right)}{d\left(x_{n+1}, x_{n+2}\right)}+\gamma d\left(x_{n+1}, x_{n+2}\right)
\end{aligned}
$$

From (5) we get:

$$
\begin{aligned}
& d\left(x_{n}, x_{n+1}\right)+\alpha \max \left\{d\left(x_{n+1}, x_{n+1}\right), d\left(x_{n+2}, x_{n}\right), d\left(x_{n+1}, x_{n}\right)\right\} \\
& \quad \geq \beta \frac{d\left(x_{n+1}, x_{n}\right)\left[1+d\left(x_{n+2}, x_{n+1}\right)\right]}{1+d\left(x_{n+1}, x_{n+2}\right)}+ \\
& +\delta \frac{d\left(x_{n+1}, x_{n}\right) d\left(x_{n+2}, x_{n+1}\right)}{d\left(x_{n+1}, x_{n+2}\right)}+\gamma d\left(x_{n+1}, x_{n+2}\right) \\
& \Rightarrow d\left(x_{n}, x_{n+1}\right)+\alpha d\left(x_{n+2}, x_{n}\right) \geq \\
& \beta d\left(x_{n}, x_{n+1}\right)+\delta d\left(x_{n}, x_{n+1}\right)+\gamma d\left(x_{n+1}, x_{n+2}\right) \\
& \Rightarrow d\left(x_{n}, x_{n+1}\right)+\alpha s d\left(x_{n}, x_{n+1}\right)+\alpha s d\left(x_{n+1}, x_{n+2}\right) \\
& \geq \beta d\left(x_{n}, x_{n+1}\right)+\delta d\left(x_{n}, x_{n+1}\right)+\gamma d\left(x_{n+1}, x_{n+2}\right) \\
& =[1+\alpha s-(\beta+\delta)] d\left(x_{n}, x_{n+1}\right) \geq(\gamma-\alpha s) d\left(x_{n+1}, x_{n+2}\right)
\end{aligned}
$$

Therefore

$$
\begin{aligned}
& d\left(x_{n+1}, x_{n+2}\right) \leq \frac{1+\alpha s-(\beta+\delta)}{\gamma-\alpha s} d\left(x_{n}, x_{n+1}\right) \\
& \text { and putting } r=\frac{1+\alpha s-(\beta+\delta)}{\gamma-\alpha s},
\end{aligned}
$$

where $0 \leq r<1$ have: $d\left(x_{n+1}, x_{n+2}\right) \leq r d\left(x_{n}, x_{n+1}\right)$.

Continuing in this way, inductively obtain:

$d\left(x_{n+1}, x_{n+2}\right) \leq r^{n+1} d\left(x_{0}, x_{1}\right)$

Since $0 \leq r<1$, and provided that $r s<1$ and taking limit as $n \rightarrow \infty$ we get $d\left(x_{n+1}, x_{n+2}\right) \rightarrow 0$. In similarity with above theorem 3.1 we can show that $\left(x_{n}\right)$ is a Cauchy sequence in complete $b$ dislocated metric space $X$. So there is a point $u$ in $X$ such that $\left(x_{n}\right) \rightarrow 0$.

Since $T$ is a continuous, we have: $T(u)=T\left(\lim _{n \rightarrow \infty} x_{n}\right)=\lim _{n \rightarrow \infty} T\left(x_{n}\right)=\lim _{n \rightarrow \infty}\left(x_{n+1}\right)=u$.

Thus, $u$ is a fixed point of $T$.

Uniqueness. Let $v$ be another fixed point of $T$.

From (4) have:

$$
\begin{aligned}
& d(T u, T v)+\alpha \max \{d(u, T v), d(v, T u), d(u, T u)\} \\
& \geq \beta \frac{d(u, T v)[1+d(v, T v)]}{1+d(u, v)}+ \\
& +\delta \frac{d(u, T u) d(v, T v)}{d(u, v)}+\gamma d(u, v)
\end{aligned}
$$


This implies that

$$
\begin{aligned}
& d(u, v)+\alpha \max \{d(u, v), d(v, u), d(u, u)\} \\
& \geq \beta \frac{d(u, v)[1+d(v, v)]}{1+d(u, v)}+ \\
& +\delta \frac{d(u, u) d(v, v)}{d(u, v)}+\gamma d(u, v) \\
& \Rightarrow d(u, v)+\alpha d(u, v)+\alpha d(v, u) \geq \gamma d(u, v) \\
& \Rightarrow[\gamma-(1+2 \alpha)] d(u, v) \leq 0
\end{aligned}
$$

Last inequality gives $d(u, v)=0$. By property of $b$-dislocated metric we have $u=v$. Hence fixed point is unique.

\section{Applications to computer security, information and communication technology}

The results obtained here are important in computer forensics and cryptography in securing data and information. It has direct applications to elliptic curve cryptography. Hence, this enhances applications in ICT and other areas of computing.

\section{REFERENCES}

[1] B.K.Dass and S.Gupta, " An extension of Banach contraction principle through rational expression.'Indian Journal of Pure and Applied Mathematics, vol. 6.no,12,pp.1455-1458,

[2] B.E. Rhoades, “A comparisonof various definitions of contractive mappings," Transactions of the American Mathematical Society, vol 226, pp. 257-290, 1977.

[3] C. T. Aage and J. N. Salunke. "The results on fixed points in dislocated and dislocated quasimetric space.” Appl. Math. Sci.,2(59):2941-2948, 2008.

[4] D. S. Jaggi. "Some unique fixed point theorems." Indian J. Pure Appl. Math., 8(2): 223-230, 1977.

[5] P. Hitzler. Generalized Metrics and Topology in Logic Programming Semantics. Ph.d. thesis, National University of Ireland,University College Cork, 2001.

[6] P. Hitzler and A. K. Seda. Dislocated topologies. J. Electr. Engin., 51(12/S):3:7, 2000.

[7] R. D. daheriya, R. Jain, M. Ughade, “ Some fixed point theorem for expansive type mapping in dislocated metric space "International Scholarly Research Network ISRN Mathematical Analysis, vol 2012,ID 376832.

[8] N. Hussain, J. R. Roshan, V. Parvaneh and M. Abbas, "Common fixed point results for weak contractive mappings in ordered b-dislocated metric spaces with applications"Journal of inequalities and Applications2013/1/48. 